\title{
Two Rare Examples of Extremely Indolent Nature of Renal Cell Carcinoma-Tumours Resectable and Curable Ten Years after Initial Diagnosis
}

\author{
Mohammad Shafi Wani*, DV Singh, Sanjay Kumar Gupta, Aditya Ashok Pradhan, Yajvinder Prasad Singh Rana, Sandeep Harkar and \\ Yogesh Kumar Swami
}

Department of Urology and Urological Oncology, Army Hospital Research and Referral New Delhi-100010, India

\begin{abstract}
We report two cases of renal cell carcinoma (RCC) that were amenable to surgical resection and cure 10 years after diagnosis. One of the cases was a 34 years old male who performed general duties in Army. He presented with left flank pain, fever, and loss of appetite of 10 days duration and on clinical examination, had a firm, non tender lump palpable in left lumbar region. The second case was 45 years old lady, a housewife, who presented with a large left flank lump. Further clinical and radiological evaluation revealed that the tumours were confined to Gerota's fascia with no evidence of lymph node or distant metastasis in either of the cases. More importantly, both the patients were found to have been diagnosed with renal tumours ten years earlier as was evident from their past medical records and old imaging, although the tumour size was relatively smaller at that time. Both the patients, however, had defaulted from undergoing surgery. They underwent radical nephrectomy at our centre and histopathological examination revealed Furhmann Grade II clear renal cell carcinoma (Stage-T2bN0M0 in the first case and Stage-T3b N0 M0) in the second case. The first case has completed two years and the second case, one and half years, respectively, of follow up and is recurrence free. There is no other reported case of renal cell carcinoma in the published literature that were left untreated for ten years and still remained not only resectable but curable also.
\end{abstract}

Keywords: Renal cell carcinoma; Indolent; Resectable

\section{Introduction}

We report two cases of renal cell carcinoma (RCC) that were amenable to surgical resection and cure 10 years after they were initially diagnosed.

\section{Case Reports}

\section{Case 1}

The first case was 34 years old serving soldier who was evaluated for left flank pain, fever and loss of appetite of 10 days duration with no family history of renal malignancy. The patient was mildly anaemic and had a firm, non tender lump palpable in left lumbar region. Contrast enhanced CT scan of abdomen showed a 16.4 x13.8 cm mass arising from left kidney with no invasion of renal vein (Figure 1). Blood biochemistry was normal. CT chest and whole body PET scan did not reveal any evidence of lymph node or distant metastasis. Past medical records of the patient showed that the patient was found to have been investigated for similar symptoms 10 years ago. Contrast enhanced CT abdomen, done in February 2000 had revealed a large enhancing lesion in the left kidney (Figure 2). The patient had defaulted from receiving any kind of treatment at that time. At our centre the patient underwent left radical nephrectomy and the histopathological examination (HPE) showed Furhmann grade II conventional clear cell variant of RCC (pT2-overall stage T2N0M0). Patient is symptom free with no evidence of disease after 2 years of follow up.

\section{Case: 2}

The second case was 45 years old lady who presented with a large left renal mass. On exploring her old medical records it was revealed that she also had been diagnosed 10 years ago as having a $7 \mathrm{~cm} \times 6.4 \mathrm{~cm}$ $\mathrm{x} 4.5 \mathrm{~cm}$ heterogeneously enhancing mass arising from lower pole of left kidney with uninvolved left renal vein and normal right kidney (Figure 3). The mass had been subjected to FNAC which had shown features of RCC. This patient also had declined to undergo surgery due to socioeconomic reasons. When she presented to our hospital, she had a large lump filling almost whole of left side of her abdomen. Contrast enhanced CT abdomen and pelvis of the patient revealed a large $15 \mathrm{~cm}$ $\mathrm{x} 10 \mathrm{~cm}$ heterogeneously enhancing mass arising from the left kidney (Figure 4). She was anaemic ( $\mathrm{Hb}-8 \mathrm{gm} \%)$ but serum biochemistry was within normal limits. Metastatic workup including CECT chest and whole body PET scan was negative. She underwent left radical nephrectomy and HPE revealed conventional clear cell variant of RCCFuhrmann grade II (pT3a-overall stage T3aN0M0). She has completed one and half year of follow up and is disease free.

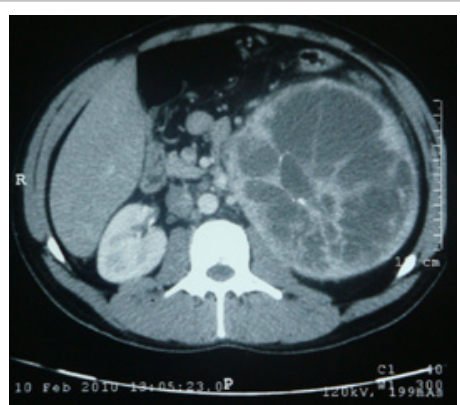

Figure 1: A large heterogeneously enhancing 16.4 x13.8 cm mass arising from left kidney with no invasion of renal vein.

*Corresponding author: Mohammad Shafi Wani, MS, Department of Urology and Urological Oncology, Army Hospital Research and Referral New Delhi, 236, Vasan Appartments Vasant Nagar, New Delhi-100010, India, Tel: 09871448314; E-mail: drshafiwani@hotmail.com

Received May 21, 2012; Accepted July 10, 2012; Published July 12, 2012

Citation: Wani MS, Singh DV, Gupta SK, Pradhan AA, Rana YPS, et al. (2012) Two Rare Examples of Extremely Indolent Nature of Renal Cell CarcinomaTumours Resectable and Curable Ten Years after Initial Diagnosis. J Cancer Sci Ther 4: 196-198. doi:10.4172/1948-5956.1000141

Copyright: @ 2012 Wani MS, et al. This is an open-access article distributed under the terms of the Creative Commons Attribution License, which permits unrestricted use, distribution, and reproduction in any medium, provided the original author and source are credited. 
Citation: Wani MS, Singh DV, Gupta SK, Pradhan AA, Rana YPS, et al. (2012) Two Rare Examples of Extremely Indolent Nature of Renal Cell Carcinoma-Tumours Resectable and Curable Ten Years after Initial Diagnosis. J Cancer Sci Ther 4: 196-198. doi:10.4172/19485956.1000141

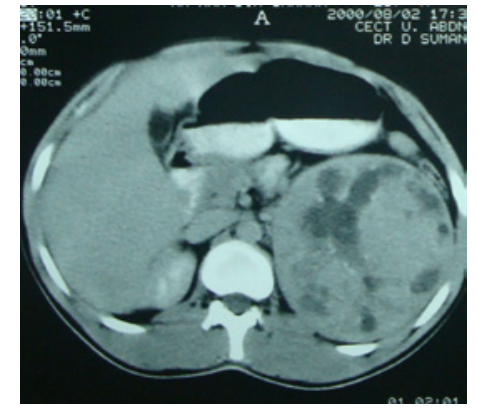

Figure 2: Ten year old CECT abdomen of the patient revealing the same mass as in Figure 1 though of smaller size.

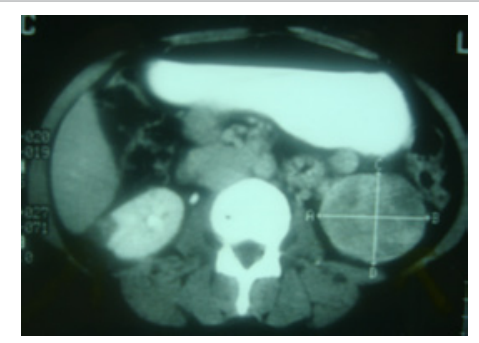

Figure 3: Heterogeneously enhancing mass arising from lower pole of left kidney with uninvolved left renal vein and normal right kidney.

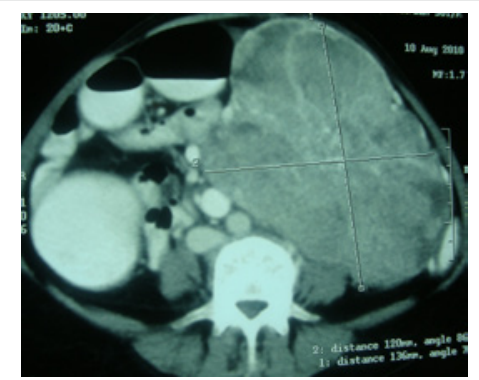

Figure 4: CECT of the same patient as in Figure 3 showing the same mass 10 years before.

\section{Discussion}

Renal cell carcinoma (RCC) accounts for $3 \%$ of all adult malignancies and exhibits 3:2 male-to-female preponderance. Traditionally, more than $40 \%$ of patients with RCC die from their cancers [1-3]. This is primarily a disease of the elderly patient, typically presenting in the sixth and seventh decades of life. It is generally believed that about $5 \%$ of all kidney cancers occur in patients younger than 40 years, while it is considered an unusual disease entity in childhood, representing only $2.3-6.6 \%$ of all renal tumours in children [4,5]. Although patients with RCC can present with a wide array of symptoms, laboratory abnormalities or both, the majority of the patients diagnosed today are asymptomatic. The indolent nature of RCC is a well known fact. Although, several recent studies have shown that most small renal masses grow slowly and metastasis is unlikely before the mass shows rapid growth, the surgery continues to remain the primary treatment modality [6]. Active surveillance can be regarded a viable and safe option in only a few small renal masses especially in patients with excessive co morbidities and short life expectancy [7]. Due to the increased detection of tumours associated with the use of imaging techniques such as ultrasound and computerized tomography, an increasing number of incidentally diagnosed RCCs are being encountered. The classic triad of flank pain, gross haematuria and palpable abdominal mass is now rarely found (6-10\%). Due to its inherent chemoresistance and insensitivity to radiotherapy, the treatment of RCC consists primarily of surgical extirpation of the tumour [7].

In the published literature, only limited experience with 'watchful waiting' or 'active surveillance' with regard to renal masses is available. Currently, the natural history of untreated localized renal tumours is being defined through active surveillance series. The majority of enhancing renal tumours undergoing active surveillance demonstrate slow interval growth. Most authors report the mean tumour growth rate to be between 0.06 and $0.21 \mathrm{~cm} /$ year for tumours $<4 \mathrm{~cm}$ in size $[2,8]$. For larger tumours, a mean tumour growth rate of $0.39 \mathrm{~cm} /$ year is reported $[7,9]$. The risk of disease progression and developing metastatic disease is the primary deterrent for initiating active surveillance of enhancing renal tumours. As such, surgical excision remains the standard of care. Tumour growth kinetics may provide a means of identifying aggressive tumours that warrant expedient intervention. However, currently no clinical predictors of future tumour growth or progression have been identified. For this reason prompt surgical intervention is advocated in all such patients who are acceptable surgical candidates [1,3].

Furthermore, it has never been reported in literature that in the absence of any severe co morbidity or a definite contraindication to surgery a large renal tumour was followed or left untreated for a period of ten years without any significant change in stage and serious perioperative morbidity when finally operated upon. Our both cases were clearly good surgical candidates at initial presentation and the tumour size was too large to have been observed or managed nonoperatively. Both the cases merited surgery considering their age at first presentation, tumour size, and stage on CECT scan. These cases are unique examples of indolent behaviour of RCC where the tumours were amenable to surgical resection 10 years after initial presentation and diagnosis. One case reported by Moslemi et al. [9] was a 54 years old man who was operated for a large right renal mass nine years after the patient had first experienced haematuria. The authors, however, could not confirm their presumption with the patient's old imaging.

Our cases represent rare instances where the tumours were left untreated due to reasons unique to each case. The first case was discouraged from getting further treatment by what he described as apparent relief of his symptoms by medicines and phobia for surgery. The second case cited her low socioeconomic status as the reason. According to the existing guidelines our cases merited surgery at initial presentation but were operated with apparent cure 10 years after initial diagnosis despite the relative unfavourable pathology (conventional clear cell variant of RCC and Furhmann grade II in both the cases). This fact supports the frequently observed slow growing nature of RCC observed in surveillance series but at the same time leaves some questions unanswered as to why the tumour remained not only resectable but also curable despite the clear cell pathology and high Furhmann tumour grade. We therefore, suggest that the currently believed determinants of disease progression and development of metastasis in RCC like age, gender, tumour characteristics on radiology and tumour pathology may not always be applicable in predicting the tumour behaviour. We also strongly believe that new molecular and histological markers of disease progression are needed as well as randomized clinical trials investigating the efficacy of active surveillance and delayed management of renal masses [10-12]. 
Citation: Wani MS, Singh DV, Gupta SK, Pradhan AA, Rana YPS, et al. (2012) Two Rare Examples of Extremely Indolent Nature of Renal Cell Carcinoma-Tumours Resectable and Curable Ten Years after Initial Diagnosis. J Cancer Sci Ther 4: 196-198. doi:10.4172/19485956.1000141

\section{Acknowledgements}

We sincerely thank all the staff members of our department whose keenness and readiness to work keep us upbeat in our observations.

\section{References}

1. Chawla SN, Crispen PL, Hanlon AL, Greenberg RE, Chen DY, et al. (2006) The natural history of observed enhancing renal masses: Meta-analysis and review of the world literature. J Urol 175: 425-431.

2. Kouba E, Smith A, McRackan D, Wallen EM, Pruthi RS (2007) Watchful waiting for solid renal masses: insight into the natural history and results of delayed intervention. J Urol 177: 466-470.

3. Lamb GW, Bromwich EJ, Vasey P, Aitchison M (2004) Management of renal masses in patients medically unsuitable for nephrectomy--natural history, complications, and outcome. Urology 64: 909-913.

4. Volpe A, Panzarella T, Rendon RA, Haider MA, Kondylis FI, et al. (2004) The natural history of incidentally detected small renal masses. Cancer 100: 738745 .

5. Renshaw AA, Granter SR, Fletcher JA, Kozakewich HP, Corless CL, et al. (1999) Renal cell carcinomas in children and young adults: increased incidence of papillary architecture and unique subtypes. Am J Surg Pathol 23: 795-802.
6. Kunkle DA, Crispen PL, Chen DY, Greenberg RE, Uzzo RG (2007) Enhancing renal masses with zero net growth during active surveillance. J Urol 177: 849853.

7. Abou Youssif T, Kassouf W, Steinberg J, Aprikian AG, Laplante MP, et al (2007) Active surveillance for selected patients with renal masses. Updated results with long-term follow-up. Cancer 110: 1010-1014.

8. Crispen PL, Viterbo R, Fox EB, Greenberg RE, Chen DY, et al. (2008) Delayed intervention of sporadic renal masses undergoing active surveillance. Cancer 112: 1051-1057.

9. Moslemi MK, Hosseini SJ, Firoozabadi MH (2010) A Huge renal cell carcinoma, nine years after its primary diagnosis and obligate observation. Case Rep Oncol 3: 326-333.

10. Hollingsworth JM, Miller DC, Daignault S, Hollenbeck BK (2006) Rising incidence of small renal masses: A need to reassess treatment effect. $J$ Natl Cancer Inst 98: 1331-1334.

11. Fujimoto N, Sugita A, Terasawa $Y$, Kato $M(1995)$ Observations on the growth rate of renal cell carcinoma. Int J Urol 2: 71-76.

12. Lee CT, Katz J, Shi W, Thaler HT, Reuter VE, et al. (2000) Surgical management of renal tumors $4 \mathrm{~cm}$. or less in a contemporary cohort. J Urol 163: 730-736. 